\title{
Use of Scanner Data to Analyze the Table Wine Demand in the Italian Major Retailing Trade
}

\author{
Francesco Torrisi \\ Department of Agricultural Economics and Land Resources, \\ University of Florence \\ Gianluca Stefani \\ Department of Agricultural Economics and Land Resources, \\ University of Florence \\ Chiara Seghieri \\ Department of Agricultural Economics and Land Resources, \\ University of Florence
}

\begin{abstract}
While the utilization of scanner data for food demand analyses has become increasingly popular in the United States, few food demand studies, and in particular none on table wine, have been conducted using scanner data in Italy. This paper presents a first attempt to estimate a demand system for selected brands of red tetra-packaged, plastic packaged, and bag-in-box table wine using scanner data providing new and useful insights into the marketing of Italian wine. Price and expenditure elasticities of Italian red table wine demand drawn from a linear almost ideal demand system are provided. Results suggest a partially loyal market of table wine, showing a tendency to substitution across brands and a degree of competition among the leading brands. [EconLit citations: Q110, Q130]. (C) 2006 Wiley Periodicals, Inc.
\end{abstract}

\section{INTRODUCTION}

The availability of scanner data from retailers enhances analysts' ability to understand consumer demand, particularly for food products. For example, Cotterill (1994) summarized the usefulness of this data for examining such issues as oligopolistic pricing strategies and promotion effectiveness. Moreover, Cotterill has noted that scanner data allows significant advances in understanding food marketing because one can now estimate firm-, brand-, and commodity-level demand models.

Utilization of this kind of data is increasingly widespread, especially in the United States where a growing literature on this field has taken place. Examples of U.S. food demand studies using this type of data include Brooker, Eastwood, and Gray (1994); Capps (1989); Chevalier (1994); Cotterill and Haller (1994); Duvall (1993); Langan and Cotterill (1994); McLaughlin and Lesser (1986); Peterson and Cotterill (1998); and Vickner and Davies (1999). In Italy, only a few works applying scanner data to food demand analysis have been published (Maietta, 2003; Marattin, 2002). In particular, to 
the best of our knowledge, no research on wine consumption using scanner data has been conducted so far.

Per capita demand for wines in Italy and other major Mediterranean wine-producing countries of the European Community has steadily declined for the last few decades. According to the Institute for Services to Agricultural and Food Market (ISMEA), wine consumption by Italian families in 2003 fell by almost 1\%. In the wake of a $4 \%$ drop in 2002, the ISMEA data for household purchases of wine and spumante (sparkling white wine) indicate overall consumption in 2003 of 857 million liters, against 862 million in $2002(-0.6 \%)$. Although the changes mentioned above are probably due to shifts in the preferences of most consumers to other drinks, packaged wine still represents an important feature of Italian household consumption. ISMEA data for the year 2002-2003 highlighted that packaged wine remained steady at levels for the previous year while bulk wine dropped by $5 \%$. In the packaged category, Denomination of Origin Controlée (DOCDOCG) wines lost ground, with consumption down by $6 \%$, compared with a recovery of $2.4 \%$ for packaged table wines. We should note that table wine refers to the most basic wine, usually available in non-glass packaging, while DOC and DOCG wines are grown in legally defined regions, are considered to be higher quality, and are packaged in glass bottles.

The primary purpose of this study is to demonstrate the usefulness of scanner data to analyze the demand relationships of selected leading brands of Italian brick-packaged (tetra-packed one liter boxes), plastic (bottle) packaged, and bag in box table wine. By estimating a brand level demand model, price and expenditure elasticities are provided in order to better understand the competitive environment of the table wine market and shed some light on the nature and differences in price competition among the selected brands and on how consumers substitute across products.

The article is organized as follows: in the following section we review the literature on demand analysis based on scanner data, the third section provides some background information on the Italian wine market, in the fourth section we describe the scanner database and introduce the methodological aspects related to the estimation of the demand system. Finally, the last section presents the main findings and concluding remarks.

\section{THE USE OF SCANNER DATA IN MARKETING RESEARCH}

During the 1980s, the registration of products through scanning of bar codes began to spread in the major retailing trade and later it become a new marketing tool able to ensure a strong competitive advantage to the holders of centralized and computerized market analysis systems. In fact, the scanning of all outgoing products from each point of sale allows the obtaining of daily information (scanner data) ideal to adopt and weigh market strategies. Furthermore it puts the data holder in a position of advantage compared to his competitors. As a consequence, agri-food businesses have been able to improve distribution and at the same time adopt more flexible marketing strategies by rapidly adjusting to changes and needs of the market.

However, due to evident economies of scale, gathering and elaboration of this information cannot be managed directly by the single brands present in the major retailing points of sale. The task has been taken over by two global market research companies, A.C. Nielsen and I.R.I. InFoscan, who since 1987 have maintained a database of all products in the major retailing trade with which they have an arrangement. The main outputs from these companies are services targeted to the needs of retailers, such as software for 
data management, detailed price databases, sales volume, market shares and promotion activities, and reports outlining the main dynamics of the particular category of interest, as well as specific trends of products and brands with long-term evaluations. All these analyses aim at interpreting the behavior and the purchase choices of consumers and the effects of manufacturers' and retailers' marketing activities.

In general, the use of these tools allows more accurate investigation of agri-food product markets and estimation of demand systems at product or brand level. Research of this type has been conducted starting from 1989 through pioneer applications, such as the survey on the consumption of different types of meat carried out by Capps (1989) in Houston, Texas. This study aimed at determining, through a historical series of observations, the relationship between demand curves of various products. A similar work, based on weekly scanner data, was carried out by Brooker and Eastwood (1994). Starting from a linear version of the Capps-Nagaya model, the authors were able to assess not only cross-price effects, but also the own and cross elasticity of the impact of advertising the examined products on TV and in local papers.

Scanner data have also proved useful in analyzing industrial organizations, seen first of all in the work by Haller (1994), who analyzed the relation between price and market share of certain brands of cheese, and in the paper by Chevalier (1994), who proposed an innovative model of oligopoly including the effects of financial investments. The analysis of neoclassic demand, in fact, focuses only on well-defined commodities, while demand at a brand level inevitably involves industrial and organizational structure.

The problem of estimating demand becomes particularly challenging when facing a differentiated oligopoly where enterprises offer brands or varieties of the same product. This is due to the interdependency of prices across the various brands, which makes the identification of supply relationships troublesome. In this perspective, Baker and Bresnahan (1985) were the first to consider the benefits of a conjoint investigation of demand and enterprises organization, in order to analyze price policies in the different oligopolies. The idea was picked up again in 1994 by R.W. Cotterill, who attempted to analyze demand and market power at the brand level by utilizing scanner data supplied by IRI and employing an AIDS specification of the demand system. The results offered agri-food marketing a tool to understand purchase behavior of consumers and therefore, a means to develop business strategy policies.

\section{THE ITALIAN TABLE WINE MARKET}

Italian consumption data for the year 2002-2003 show that packaged table wine represents the main share of household wine consumption (56\%), to which we can add another $15 \%$ of bulk wine (source ISMEA). Not surprisingly, table wine value is moderate compared to its volume. In fact, only $42 \%$ of total expenditure on wine and sparkling white wine is from packaged table wines, while bulk wines' share represents $9 \%$ of total value. During the same period, $64 \%$ of table wine consumed by Italian families was purchased in the main formats of modern distribution, that is, in supermarkets and mega stores. Indeed modern distribution doesn't leave much space for traditional food shops, which account for only $10 \%$ of sales, of which $6 \%$ is ascribable to wine houses, showing the growing concentration of supermarket share, especially for wines in the lowest price range.

The Italian table wine sector is characterized by the strong presence of cooperatives and a large number of family-managed wineries. However only few large firms such as G.I.V., Gruppo Coltiva, Caviro, Cantine Riunite, Due Tigli, and Zonin are potentially 
able to operate in the national and international market; others of smaller size are trying to enlarge the area of their market, with uncertain success. The most widespread business structure is represented by the wine producers' cooperatives where wine growers are the main members. Cooperatives' policy in the last five years has focused on shifting the production mix towards packaged wine, compared to bulk wine, and towards highquality wine compared to table wine. Small and medium firms are upgrading their offers by producing higher-quality wines. However, this strategy has not been very successful because of minimal investment in promotion and branding policies due to the limited financial resources of this type of firm.

\subsection{Product Policies}

Present product policies in the table wine sector are based mainly on the standardization of product quality, through investments in production technology. Special attention has been paid to packaging, not only in terms of increased practicality (multi-tetra packaging, easy open-close packaging, $250 \mathrm{ml}$ boxes), but also in terms of improving communication through improved product image and information concerning quality, origins, and production techniques.

During the last few years, producers have modified strategies related to the range of products, which used to include a large number of stock keeping units (SKUs), with different brands and various sizes. This is because modern distribution tends to limit the number of SKUs for each brand in order to maintain high bargaining power towards suppliers. In particular, in the case of tetra packaging, modern distribution usually supplies the leader brand, a commercial or low-price brand (generally red wine) and an average priced product.

The range of enterprises that sell their products on the domestic market and mainly through modern distribution, has also decreased. Conversely, the supply of a complete range of products represents an essential characteristic for enterprises operating in the foreign market (among these G.I.V., Zonin, and Schenk) in order to increase their sales, offering to importers the advantage of a limited number of suppliers, therefore saving in logistics. Product portfolio choices offered by producers follow three main guidelines:

- Production of only one brand (in three types: white, red, and light red) with a traditional taste, which is potentially suitable for all consumers. However, this typically fails to satisfy all consumers, who are unable to choose different packaging or wine styles.

- Production of different wines from various regions, typically providing the most common varieties from each region. This is the principle followed by Zonin and the Gruppo Coltiva.

- Different wines from the same region, following the tradition of the consumption area. This is the case of S. Matteo and Cielo (which also has a wide range of wines from other regions).

Generally consumers tend to prefer wines of their own region, looking more at the type of wine, than at the brand. The supply of nationally known wines sought after because of the renown of the brand is very limited. Product innovation has been and continues to be a very important factor in determining business success, as long as it is coherent with the image of the firm's brand and the pre-existing products' portfolio. 


\subsection{Pricing Policies}

Price, as a parameter for product positioning, is the key element of strategy of a large part of the businesses in the sector. Positioning the same types of product at different price ranges seems to reduce demand and confuse the consumer. However, table wines are often sold at higher prices than DOC wines.

The price variable together with a commitment to brand policy represents the main reason for the success of tetra-packaged wines; in this case a careful positioning considering all the parameters of the marketing mix leads to the development of a segment with its own distinctive value. In this case consumers tend to rely on the advice of the personnel in the specialized wine shops and to buy according to on the brand name. Some chains have offered a clear separation between the DOC wines and table wines, positioning the first type as in a typical wine shop atmosphere. Others have divided wines according to the region of origin and the color, attempting to avoid overcrowding and confusion on shelves.

\subsection{Analysis of Threats and Opportunities}

The sector of table wines is now mature and the analysis of threats and opportunities reveals that the first prevail on the second one. The strongest threat for the whole table wine sector is the growing preference for regionally based quality wines to the detriment of table wines, even if these still have the highest market share. Furthermore, we are witnessing an acceleration in the recognition of various DOC wines that, together with other regional wines, are improving their quality and reducing the production of simple table wine.

Other threats are the weak barriers permitting the entrance into the market of poorly qualified producers; the reduced number of occasions in which wine is consumed (fewer traditional meals at home); the growing bargaining power of modern distribution that exerts pressure on the producers' margins; the development potential of competitive products taking advantage of fragmentation in the Italian wine market; the growing price/ quality ratio of competitors' wines (Chilean, Australian, and Argentinean); and the strong competition within the modern distribution channels with low price products, which, on the whole, worsen the overall image of the product.

Among the opportunities for the sector, we can point out the general interest of Italian firms for expanding into global markets, in particular toward Eastern Europe and Asia, which have high development potential. The growing number of Internet users, which represent a potentially new target group of consumers, may offer other opportunities. Presently, online sales are mainly carried out through distributors, especially wine houses and virtual shopping centers. However, it is believed that in future business-to-business sales will take place directly from producer to distributor or retailer, as it is already happening in other sectors. These prospects may add to the bottom line not only for wine growers but also for the regions where they operate.

Other opportunities mainly involve aesthetic aspects of the product (packaging). In fact, tetra packaging will continue to expand as consumers will confer to it the same value as to glass bottles; similarly, the trade is likely to pay growing attention to the ease of transport and assortment arrangement and to the lower handling costs compared to the bottled product.

\section{DATA AND METHODS}

The econometric analysis of Italian wine demand relies on scanner data providing the monthly total of observed purchases for all brands supplying brick-packaged table wine 
in Italian supermarkets over the period 2002-2004. These data are provided by IRI InfoScan. Information is given for large territorial aggregates, in this case, 51 Italian provinces from 16 regions. These aggregates represent $76 \%$ and $90 \%$, respectively, of sales and cover the weighted average of all Italian supermarkets. In particular, for each product (or brand) analyzed, the data set consists of the monthly sales volume in the period 20022004, the price that prevailed during the period and also the price and volume sold during promotional activity (e.g., the price and volume of items whose original prices have been reduced by at least 5\% for a period of no more than 6 weeks).

From a first descriptive analysis, the Italian wine market appears highly segmented, since there are many brands and even products of the same brands can differ depending on packaging format, price and so on. Moreover, estimating demand for each individual size or variation of consumer product is generally not practical, and attempting to do so would often lead to imprecise parameter estimates, due to likely multicolinearity, while we are interested in highlighting the main strategic issues. Thus, to keep the analysis to a manageable level we estimated a demand system using only four leading brands: Castellino, Tavernello, Ronco, and Private Label. These are the brands with the highest share of sales volume among all the brands of red table wine sold in three different kinds of packaging (bag in box, plastic, and brick). The rest of the fringe brands are aggregated into an "all other" brand category. Data related to some characteristics of Castellino, Tavernello, Ronco and Private Label are reported in Table 1.

In the period 2002-2003, proportions of volume sold are almost similar across Castellino, Ronco, and Private Label, with 11\%, 9\%, and 10\%, respectively. Conversely, Tavernello seems to behave differently, its percentage of volume sold is significantly higher (39\%) than the other brands. This difference is also true in the period 2003-2004, where, in addition, Tavernello and the Private Label are the only two brands experiencing an increase in the share of volume sold: $41 \%$ and $12 \%$, respectively, against $9 \%$ for both Castellino and Ronco. The pattern among the four brands is somewhat clear, since Tavernello can be considered the first and most popular brand of table wine in the market. It has also a good quality/price ratio. On the other hand, Ronco, although being the besttasting brand, is at the same time the most expensive one (i.e., in both periods, the mean price of Ronco is the highest among the other brands). These last features might be also the reason why, during a period of price promotion, the pattern of volume sold is completely reversed: consumers might decide to purchase the best-quality brand during a promotion. Consequently, the proportions of volume sold of Tavernello decreased (12\%

TABLE 1. Proportion of Sales Volume, Promotional Sales Volume, and Mean Prices by Selected Brands of Red Table Wine and by Two Time Periods (2002/2003-2003/2004)

\begin{tabular}{|c|c|c|c|c|c|c|c|c|}
\hline & \multicolumn{4}{|c|}{$2002 / 2003$} & \multicolumn{4}{|c|}{$2003 / 2004$} \\
\hline & $\begin{array}{c}\text { Sales } \\
\text { volume }\end{array}$ & A & B & $\begin{array}{l}\text { Mean } \\
\text { prices }\end{array}$ & $\begin{array}{c}\text { Sales } \\
\text { volume }\end{array}$ & A & B & $\begin{array}{l}\text { Mean } \\
\text { prices }\end{array}$ \\
\hline Total red table wine* & 38133284 & $100 \%$ & $10 \%$ & 1.040 & 38936247 & $100 \%$ & $11 \%$ & 1.105 \\
\hline Castellino & 4047522 & $11 \%$ & $22 \%$ & 1.289 & 3315294 & $9 \%$ & $21 \%$ & 1.297 \\
\hline Private Label & 3905456 & $10 \%$ & $14 \%$ & 0.962 & 4511907 & $12 \%$ & $16 \%$ & 0.979 \\
\hline Ronco & 3248745 & $9 \%$ & $31 \%$ & 1.305 & 3350229 & $9 \%$ & $26 \%$ & 1.377 \\
\hline Tavernello & 14867479 & $39 \%$ & $12 \%$ & 1.194 & 16118540 & $41 \%$ & $13 \%$ & 1.213 \\
\hline
\end{tabular}

Note. *Packaged as bag in box, brick, and plastic bottle

A: $\%$ of sales volume, B: $\%$ of sales volume during promotional activities. 
in 2002-2003 and 13\% in 2003-2004), while, on the contrary, the sales of Ronco seem to be positively affected by the promotional activity (the percentages of volume sold became $31 \%$ in $2002-2003$ and $26 \%$ in 2003-2004).

Trying to estimate the statistical relationship between the quantity of table wine purchased, the price, the promotional activities and other determinants of demand, requires the analyst to specify a functional form for the market-level demand equations. In our context, the study of cross-category demand interdependencies can be achieved by estimating a conditional (that is conditional to the expenditure for table wine) demand system from which the cross-price elasticity of brands can be subsequently determined.

Among the econometric demand systems, one well-known model is the almost ideal demand system (AIDS) (Deaton \& Muellbauer, 1992). This model has attracted a great deal of attention, and has been extensively applied to cross-sectional and time series data. According to the AIDS specification, the dependent variables are expenditure shares for each of the five wines (four brands plus the all others category) measured for each of the 25 Italian provinces over a period of 25 months. The independent variables are logs of the per liter prices of the wines specific for each location and total expenditure for the group of wines.

In addition to the abovementioned data, we identify two more regressors believed to be important wine demand determinants:

1. Monthly mean temperatures (Ufficio Centrale di Ecologia Agraria (UCEA), http:// www.ucea.it) for each province.

2. Percentage of volume sold during promotional activities for each wine brand.

These two variables are explicitly included in our demand model as demand shifters. All the variables used in the econometric analysis are displayed in Table 2. To specify the demand for the different brands of wine we use the linear form of the AIDS model. Thus, in our application, the AIDS specification becomes:

$$
w_{i l t}=\alpha_{i l t}+\sum_{j=1}^{N} \gamma_{i j} \log \left(p_{m l t}\right)+\beta_{i} \log \left(\frac{y_{l t}}{P_{l t}}\right)+\varepsilon_{i l t}
$$

TABLE 2. Description of the Variables Used in the Econometric Analysis

\begin{tabular}{ll}
\hline Variable & Description \\
\hline P_OTHER & Natural log of Other wines \\
P_CAST & Natural log of Castellino \\
P_PL & Natural log of Private Labels \\
P_RONCO & Natural log of Ronco \\
P_TAV & Natural log of Tavernello \\
EXP & Natural log of the Italian red wine expenditures divided by the Stone's index \\
PV_OTHER & Percentage volume of Other wines sold in promotion \\
PV_CAST & Percentage volume of Castellino sold in promotion \\
PV_PL & Percentage volume of Private Labels sold in promotion \\
PV_RONCO & Percentage volume of Ronco sold in promotion \\
PV_TAV & Percentage volume of Tavernello sold in promotion \\
PV_TEMP & Monthly mean temperatures \\
\hline
\end{tabular}


where $p=\left(p_{1}, \ldots, p_{N}\right)$ is a vector of prices for the five brands selected, $x, y$ denotes expenditures on the five wines, $w_{i l t}=p_{i l t} x_{i l t} / y_{i l t}$ is the budget share for the $i^{\text {th }}$ wine consumed in the $l^{\text {th }}$ city at time $t, P$ is the Stone's price index, and $\varepsilon_{i l t}$ is a vector of stochastic errors $N(0, \Omega)$ distributed.

Demand shifters are incorporated into the model by specifying (see Heien \& Wessels, 1988):

$$
\alpha_{i l t}=\alpha_{0 i}+\sum_{k=1}^{K} \lambda_{i k} Z_{k l t} \quad i=1, \ldots, 5
$$

where $Z_{k l t}$ is the $k^{\text {th }}$ demand shifter in the $l^{\text {th }}$ city at time $t$.

The model parameters were initially estimated equation by equation by ordinary least squares, pooling the data from the 25 provinces. However, the panel nature of the data suggested a more efficient estimator such as the fixed effect panel estimator that takes into account market specificities related to each different province. A second round of estimates was obtained employing this estimator. Finally, in order to test the economic restriction of homogeneity and symmetry on the demand system, data were transformed by subtracting the group (province) mean from each variable and a seemingly unrelated regression estimator (Zellner, 1962) was employed to estimate the system. Moreover, due to adding-up restrictions, we drop one demand equation (all other brands, which we decided not to show in order to draw attention to the other more important and meaningful brands) from the system and estimate a system with $\mathrm{N}-1$ demand equations. Elasticities were calculated from the demand system parameters employing the formulas given by Green and Alston $(1990,1991)$ while elasticity standard errors were obtained through a bootstrapping procedure. All the elaborations were made using LIMDEP software (www.limdep.com), version 3.0.14.

\section{RESULTS}

Parameter estimates together with their standard errors are shown in Table 3.

In all the equations, temperature seems not to have a significant impact on wine demand: its parameters in each equation are not statistically significant at the 5\% level. Conversely, the other demand shifter, the volume sold during promotional activities, seems to significantly influence the consumption of each product. In general, the demand for any brand reacts positively whenever its own volume sold in promotion increases, on the other hand, the demand decreases as the volume of any other brand sold in promotion increases.

In particular, the demand for Ronco wine shows a positive relation with the loyalty index (the estimated coefficient of the variable "PV_RONCO" is 0.045), probably due to the higher price of the wine that positions it in a range of more sophisticated consumers indifferent towards the promotional policies of other competitors. In acknowledgement of this, there is the no relation with the variation of prices of the Private Labels, occupying the lower price range and addressing a different type of consumer. Furthermore the demand for Ronco wine appears to grow with the increase in price of its most direct competitors, Tavernello and Castellino. The relation between demand and overall expenditure, only in this case, is significant and, on top of this, positive, demonstrating how the purchase of Ronco is linked to higher expenditures on wine. 
TABLE 3. Parameter Estimates and Standard Errors of the Linear AIDS

\begin{tabular}{lcccc}
\hline Variable & CAST & PL & RONCO & TAV \\
\hline P_OTHER & -0.03421 & 0.02495 & -0.00284 & 0.04384 \\
& $(-0.01072)$ & $(0.00903)$ & $(0.01052)$ & $(0.01400)$ \\
P_CAST & -0.10991 & 0.01087 & 0.02968 & 0.10356 \\
& $(-0.01528)$ & $(0.00918)$ & $(0.01034)$ & $(0.01482)$ \\
P_PL & 0.01087 & -0.08543 & -0.00665 & 0.05626 \\
& $(0.00918)$ & $(0.01086)$ & $(0.00840)$ & $(0.01204)$ \\
P_RONCO & 0.02968 & -0.00665 & -0.12364 & 0.10345 \\
& $(0.01034)$ & $(0.00840)$ & $(0.01381)$ & $(0.01335)$ \\
P_TAV & 0.10356 & 0.05626 & 0.10345 & -0.30711 \\
& $(0.01482)$ & $(0.01204)$ & $(0.01335)$ & $(0.02432)$ \\
EXP & -0.00772 & 0.00151 & 0.03176 & 0.00560 \\
& $(0.00498)$ & $(0.00393)$ & $(0.00537)$ & $(0.00622)$ \\
PV_OTHER & -0.03795 & -0.00055 & -0.03135 & -0.06292 \\
& $(0.00972)$ & $(0.00769)$ & $(0.01047)$ & $(0.01217)$ \\
PV_CAST & 0.06186 & -0.00957 & -0.00757 & -0.01309 \\
& $(0.00602)$ & $(0.00417)$ & $(0.00532)$ & $(0.00666)$ \\
PV_PL & 0.0586 & 0.02403 & 0.00357 & -0.01918 \\
& $(0.00579)$ & $(0.00519)$ & $(0.00604)$ & $(0.00731)$ \\
PV_RONCO & -0.00093 & -0.01687 & 0.04501 & -0.01358 \\
& $(0.00513)$ & $(0.00411)$ & $(0.00626)$ & $(0.00659)$ \\
PV_TAV & 0.00168 & -0.01708 & -0.00856 & 0.08150 \\
& $(0.00763)$ & $(0.00609)$ & $(0.00802)$ & $(0.01017)$ \\
PV_TEMP & 0.00002 & 0.00001 & -0.00005 & 0.00000 \\
& $(0.00002)$ & $(0.00002)$ & $(0.00002)$ & $(0.00003)$ \\
\hline
\end{tabular}

Note. Standard errors in parenthesis

On the contrary, loyalty for Private Label is supported only by convenience reasons. It is evident how demand decreases when more expensive brands carry out promotional activities, temporally co-locating themselves in the same price range and becoming price competitive with Private Label. This last case represents the only opportunity for Tavernello, Ronco, and Castellino to enter in competition with the Privates, while it is difficult for the Privates to gain loyal consumers from other brands because there is no relationship between the increase in price of the most expensive competitors and the demand of the Private Labels. Castellino and Tavernello, the two brands of the Cavino S.c.a.r.l. are in an intermediate position, representing two goods that are substituted for each other according to price. In particular, the demand of the first grows as the price of both Tavernello and Ronco rises, while there isn't a significant relationship with the Private Labels. Furthermore, the Castellino brand shows a certain degree of consumer loyalty, since there is no relation between the increase of promotional activities and its demand. Tavernello, the leader brand in terms of volume sold, is a different case, since it increases its commercial interest when its competitors raise their price, including Private Label, while its demand decreases when other brands are promoted. Fundamentally, there is less loyalty to the product, whose success is linked to the quality/price ratio considered optimal by consumers. It is possible to obtain further details for the market analysis by looking at the data on expenditure elasticities and direct and cross price compensated elasticity. 
TABLE 4. Own and Cross-Price Brand Elasticities of Demand

\begin{tabular}{lccccc}
\hline Variable & OTHER & CAST & PL & RONCO & TAV \\
\hline OTHER & -1.10 & -0.13 & 0.12 & 0.00 & 0.24 \\
& $(0.13)$ & $(0.05)$ & $(0.06)$ & $(0.06)$ & $(0.08)$ \\
CAST & -0.29 & -1.99 & 0.11 & 0.28 & 0.97 \\
& $(0.10)$ & $(0.20)$ & $(0.10)$ & $(0.10)$ & $(0.15)$ \\
PL & 0.24 & 0.10 & -1.82 & -0.07 & 0.53 \\
& $(0.13)$ & $(0.11)$ & $(0.15)$ & $(0.10)$ & $(0.13)$ \\
RONCO & -0.10 & 0.25 & -0.10 & -2.21 & 0.86 \\
& $(0.13)$ & $(0.10)$ & $(0.09)$ & $(0.18)$ & $(0.15)$ \\
TAV & 0.10 & 0.23 & 0.12 & 0.23 & -1.69 \\
& $(0.04)$ & $(0.04)$ & $(0.03)$ & $(0.04)$ & $(0.06)$ \\
\hline
\end{tabular}

Note. Bootstrap standard errors in parenthesis.

Own price elasticities are negative as expected and range from -1.10 to -2.21 , indicating that small changes in the price of table wine elicit quite large changes in quantities purchased. The most elastic brand seems to be Ronco with a price elasticity of -2.21 , while the least elastic is Tavernello with -1.69 . These results seem to confirm the information obtained with the descriptive analysis. The cross elasticity of prices indicates how certain brands are strongly substituted. Tavernello is the only good that is substituted for all the other brands. More in detail, even with an elasticity $<1$, an increase in price of Tavernello corresponds to greater increases in demand for its competitors. This is particularly true for Castellino, the other brand of Cavino, since if Tavernello's price grows by $1 \%$, consumers will increase the purchase of Castellino by almost the same $0.97 \%$. However, Castellino is a stronger substitute for Tavernello than the other way around, because we have an increase of $0.23 \%$ of sales of Tavernello following an increase in price of Castellino of $1 \%$. This is explained by the fact that Tavernello occupies a much larger share of the market compared to Castellino. This combined effect of price/demand variation allows Cavino S.c.a.r.l. to compensate for loss in shares by following a policy of joint increases in price and at the same time maintaining a dominant position in the market as unquestioned leader of the sector. On the contrary, a rise in price of Private Labels seems to have less effect on demand for other brands, on the order of 0.12 . It is therefore possible to see some clear trends within the demands for various brands of red table wine, and, on the whole, the analysis of own and cross elasticity suggests the idea of a partially loyal market, with a certain tendency to substitution and with evident competition among leading brands.

\section{LIMITATIONS AND FUTURE RESEARCH}

Possible limits of this study are mainly due to potential measurement problems with the scanner data. A first problem concerns price surveys that cannot include discounts, such as coupons or loyalty cards or promotional campaigns of only a few days, which might cause a non-generalized reduction in price and therefore are not detectable in the supplied data. In these cases, sometimes the price is recorded as the most commonly occurring price (typically the price with a club card), other times average revenue is recorded. In addition, Infoscan collects and reports data weekly, while products' price variations in the 
major retailing trade may be more rapid, e.g., promotions at some retailers run Sunday to Saturday, while others run on a Thursday to Wednesday schedule. Thus, it is quite possible that the shelf price reported in a given week will only correspond to the actual shelf price for a portion of the reported week. We tried to overcome this problem and by taking into account the possible effect of promotional activities on consumer's price sensitivity by introducing into the demand equations the percentage of volume sold during promotional activities. Another common problem in using scanner data, supplied as temporal and geographic aggregates, is that they don't allow an individual estimate of consumer's demand.

Another issue is that the estimated own and cross-price elasticities of aggregate demand for periods like a weekly could possibly be dominated by the consumer response to short term price promotions. In particular, using data aggregated across time might overestimate the elasticities because consumers often buy large quantities of items, which are on sale and take them into household inventories. Since the demand elasticities we estimate are not for the purpose of antitrust analysis we prefer to concentrate our study on our real objectives and we ignore such short-term effects.

Furthermore, data for each single point of sale are never supplied, but they are provided as large aggregates (e.g., municipality, province, or region). Clearly if independent price decisions are made by stores within geographical areas, the price and quantity observed in the data (reported as average values) will not correspond to the price charged by the individual store. Consequently, the estimated aggregate demand curve will not take into account differences across stores. Another technical drawback of the research could concern the endogeneity of both price and expenditure in demand estimation, which could lead to biased parameter estimates. The usual practice is to treat prices and expenditures as exogenous variables. For example, economists focusing on consumer behavior often ignore the problem of price endogeneity and treat the consumers as price-takers, i.e. as having no impact on prices. However, as already mentioned, households, by making purchase decisions based on promotional activities could affect prices. Besides price endogeneity, the endogeneity of household expenditures can also be a problem. In particular, our demand analysis is conditional on just packaged table wine expenditure, which in turn depends on the level of prices of the five brands investigated. Dhar et al. (2002) were the first to undertake the potential problem of endogeneity using brand level data. Their empirical analysis of retail scanner data suggested that both price and expenditure endogeneity significantly impacted the demand parameter estimates.

Thus, looking at future research directions, it would be useful to include in our work appropriate tests for both price and expenditure endogeneity. However, if taking into account the endogeneity in the demand model would generate more efficient parameter estimates it also would lead to a system of equations including price reaction functions difficult to specify with the available data. Thus, given the complexities and time requirement of estimating such a system of equation, it remains important to understand the trade-off between demand specification and empirical tractability.

\section{DISCUSSION}

This research demonstrates that an analysis of scanner data at the brand level can combine two sub-fields of economics: the study of demand and the analysis of the firm's organization, in order to offer a newer and more relevant investigation tool for the marketing of agri-food products. In particular the analysis of the demand for red table wine 
(in tetra, bag in box, and plastic), in the Italian major retailing trade, has highlighted a structured market, managed both by the two leader firms and by the major retailing trade itself through Private Labels and with the degree of substitution suggesting the presence of a competition system, whose grade of perfection is difficult to define. However, this study is still a work in progress and is subject to possible future developments such as: the completion of the analysis of the supply through the individual measurement of the market power of single brands and of the role of price leaders and perhaps a more accurate model specification. We do see the value of brand-building for the largest brands in the ability to reduce the competitive effects of other brands. The retailers, while having reasonable market share through their Private Labels are unable to compete at higher prices or to gain by the promotional activities of other nationally branded wines. Much of the previous research in wine brands looks at bottle wine at higher price points than the table wines we investigate here. We are able to show that marketing activities for these near-commodity products seems to have a positive effect.

\section{REFERENCES}

Baker, J.B., \& Bresnahan, T.F. (1985). The gains from merger or collusion in product-differentiated industries. Journal of Industrial Economics, 33, 427-443.

Brooker, J.R., Eastwood D.B., \& Gray M.D. (1994). The impact of advertising on consumer demand for beef: An application of scan data. Journal of Food Products Marketing, 2, 17-35.

Capps, O., Jr. (1989). Utilizing scanner data to estimate retail demand functions for meat products. American Journal of Agricultural Economics, 71, 750-760.

Chevalier, J.A. (1987). A globally flexible, Almost Ideal Demand System. Journal of Business and Economic Statistics, 5, 233-242.

Chevalier, J.A. (1994). Capital structure and product market competition: An empirical study of supermarket pricing. Ph.D. thesis, Harvard University.

Cotterill, R.W. (1994). Scanner data: New opportunities for demand and competitive strategy analysis. Agricultural and Resources Economic Review, 125-139.

Cotterill, R.W., \& Haller, L.E. (1994). Market strategies in branded dairy product markets. In R.W. Cotterill (Ed.), Competitive strategy analysis for agricultural marketing cooperatives, (pp. 99144). Boulder: Westview Press.

Deaton, A., \& Muellbauer, J. (1992). Economics and consumer behaviour. Cambridge: Cambridge University Press.

Dhar, T., Chavas, J.P., \& Gould, B.W. (2002). An empirical assessment of endogeneity issue in demand analysis for differentiated products. University of Connecticut, Food Marketing Policy Center, Research Report No. 66.

Duvall, J.S. (1993). A study of horizontal and vertical competitive influence on retail price in the U.S. soft drink industry. M.S. thesis, University of Connecticut.

Green, R., \& Alston, J.M. (1990). Elasticities in AIDS models. American Journal of Agricultural Economics, 72, 442-445.

Green, R., \& Alston, J.M. (1991). Elasticities in AIDS models: A clarification and extension. American Journal of Agricultural Economics, 73, 874-875.

Haller, L.E. (1994). Branded product pricing strategies in the catsup and cottage cheese industries: The effects of brand share and cooperative presence. Ph.D. dissertation, University of Connecticut.

Heien, D.M., \& Wessels, C.R. (1988). The demand for dairy products: Structure, prediction, and decomposition. American Journal of Agricultural Economics, 70, 219-228.

IRI-InFoscan, Dati vendite vino da tavola 2002-2004.

ISMEA-Indice dei Prezzi alla Produzione 2002-2004.

Langan, G., \& Cotterill, R.W. (1994). Estimating brand level demand elasticities and measuring market power for regular carbonated soft drinks. Proceedings of the American Agricultural Economics Association annual meeting, August 7-10, San Diego.

McLaughlin, E., \& Lesser, W. (1989). Experimental price variability and consumer response: Tracking potato sales with scanners. Cornell University, Agricultural Staff Paper 86-28. 
Maietta, O.W. (2003). The hedonic price of fair-trade coffee for the Italian consumer. Proceedings of the International Conference Agricultural Policy Reform and the WTO: Where are we heading?. Capri (Italy), June 23-26.

Marattin, L. (2002). An econometric analysis of aggregate demand in Italy from 1980 to 2000: The impact of advertising. MSc thesis at Department of Economics, University of Warwick.

Peterson, E.B., \& Cotterill, R.W. (1998). Incorporating flexible demand systems in empirical models of market power. University of Connecticut, Food Marketing Policy Center, Research Report No. 43.

Vickner, S.S., \& Davies, S.P. (1999). Estimating market power and pricing conduct in a productdifferentiated oligopoly: The case of the domestic spaghetti sauce industry. Journal of Agricultural and Applied Economics, 31, 1-13.

Zellner, A. (1962). An efficient method of estimating seemingly unrelated regression and tests for aggregation bias. Journal of the American Statistical Association, 57, 1962.

Francesco Torrisi is Researcher at the Department of Agricultural Economic and Land Resources at University of Florence. He holds a PhD in Economics and Forest Management from the University of Florence. His current research interest includes wine market and consumer behavior.

Gianluca Stefani is Associate Professor at the University of Florence. He holds a Bsc in Agricultural Sciences (Florence, Italy), MSc in Agricultural Economics (Reading, UK), and a PhD in Agricultural Economics and Policy (Bologna, Italy). His current research interest regards food economics and consumer economics.

Chiara Seghieri is Researcher at the Department of Agricultural Economic and Land Resources at the University of Florence. She holds a PhD in Applied Statistics from the Department of Statistics, University of Florence. Her current research interests include quality of life studies, spatial poverty analysis and demand analysis.

The work is the joint effort of the three authors. However, Francesco Torrisi wrote paragraphs 1, 2, 3, 6, and 7, Gianluca Stefani wrote paragraph 5, and Chiara Seghieri wrote paragraph 4. 